\title{
Analysis of effects of Smoking on Lung Function, and Respiratory Muscle Strength of Pakistani Youth
}

\author{
Murad Mehmood*, Muhammad Ahmad Shahid and Ahmar Saleem \\ Services institute of medical sciences Lahore, Pakistan
}

Received: 阱 August 04, 2018; Published: 眥 August 13, 2018

*Corresponding author: Murad Mehmood, Services institute of medical sciences Lahore, Pakistan

\begin{abstract}
Introduction: In the present era, cigarette smoking is a major but preventable cause of death. Despite being aware of its harmful and hazardous effects, many young adults begin experimenting with cigarettes at a very early age and then adopt it as a regular habit.

Objectives of the Study: The basic objective of our study is to analyze the effects of smoking on lung function, and respiratory muscle strength of Pakistani youth.

Methodology of the Study: This study was conducted at Services institute of medical sciences, Lahore during 2017. Youth male subjects aged 12 to 18 years participated in this cross-sectional study. Socio-demographic values and medical history of the selected patients were recorded clearly. Prior to participation in this study, each subject signed an informed consent form to comply with the ethical guidelines.

Results: Most subjects started cigarette smoking between the ages of 15 to 18 years. The most common duration of cigarette smoking was $1-3$ years. Three major parameters, chest expansion, lung function using spirometry, and respiratory muscle strength, were compared and these all are high in smokers.

Conclusion: It is concluded that most of the people started smoking in young age due to environmental and social factors. It is also observed that chest expansion is greater in smokers as compared to non-smokers and smokers suffer ore from respiratory diseases as compared to non-smokers.
\end{abstract}

Keywords: Smokers; Social; Lungs; Respiratory

\section{Introduction}

In the present era, cigarette smoking is a major but preventable cause of death. Despite being aware of its harmful and hazardous effects, many young adults begin experimenting with cigarettes at a very early age and then adopt it as a regular habit [1]. Cigarette smoking is an important worldwide health problem, and it has been reported that 1.7 million Thai youths currently smoke. This problem is compounded by the fact that the rate of cigarette smoking in young people continues to steadily increase. Cigarette smoking carries major health risks with the most cause-specific mortalities being those of respiratory and cardiovascular diseases. Therefore, smoking habits may affect the respiratory function of youths [2]. Earlier reports have indicated that in young adults, relatively small amounts of cigarette smoke can cause deficit in lung functions [3]. Smoking 15 cigarettes per day in males has been associated with $4 \%$ decline in forced mid expiratory flow as compared to those who never smoked. Since inhaling cigarette smoke has been shown to produce acute changes in the lung including alterations in resistance to airflow, cough, and irritation of the airway, the early stage of smoking might affect the respiratory function of youths [4]. However, there have been few studies which have investigated the effect of smoking on pulmonary function in adolescents. In previous studies, cigarette smoking was found to influence the lung function of the adolescent boys and girls. Those studies found that FEV1/FVC decreased in adolescent smokers of both sexes. Only the pulmonary function test with a spirometer was measured in those studies [5]. Therefore, to clarify the effect of smoking on the respiratory function of smoking and non-smoking youths, we measured and compared their chest expansion, the lung function test using a spirometer, and respiratory muscle strength to learn more about the dangers of cigarette smoking [6].

\section{Objectives of the Study}

The basic objective of our study is to analyze the effects of smoking on lung function, and respiratory muscle strength of Pakistani youth.

\section{Methodology of the Study}

This study was conducted at Services institute of medical sciences, Lahore during 2017. Youth male subjects aged 12 to 18 years participated in this cross-sectional study. Socio-demographic values and medical history of the selected patients were recorded 
clearly. Prior to participation in this study, each subject signed an informed consent form to comply with the ethical guidelines. The information on smoking habits was obtained through interviews (Table 1). Subjects who currently smoked cigarettes were classified as smokers and those without a history of smoking cigarettes were classified as non-smokers. The respiratory function test consisted of the measurement of chest expansion, the lung function test using spirometry, and respiratory muscle strength. For chest expansion measurements of circumference and diameter, subjects were instructed to fully inhale and exhale in the standing position.

Table 1: Comparison of factors between smokers and nonsmokers.

\begin{tabular}{|c|c|c|}
\hline & $\begin{array}{l}\text { Non Smokers } \\
\text { (Mean } \pm \text { SD) }\end{array}$ & $\begin{array}{c}\text { Smokers } \\
(\text { Mean } \pm \text { SD) }\end{array}$ \\
\hline \multicolumn{3}{|c|}{ Chest Expansion } \\
\hline \multicolumn{3}{|c|}{ Chest Circumference } \\
\hline Axilla (cm) & $5.71 \pm 1.62$ & $4.68 \pm 2.03$ \\
\hline Xiphoid process $(\mathrm{cm})$ & $5.32 \pm 1.68$ & $5.18 \pm 2.22$ \\
\hline $10^{\text {th }}$ Costal cartilage $(\mathrm{cm})$ & $4.66 \pm 1.19$ & $4.24 \pm 2.03$ \\
\hline \multicolumn{3}{|c|}{ Chest Diameter } \\
\hline $\mathrm{AP}(\mathrm{cm})$ & $3.56 \pm 0.61$ & $3.06 \pm 0.69$ \\
\hline ML $(\mathrm{cm})$ & $3.51 \pm 0.44$ & $3.18 \pm 0.85$ \\
\hline \multicolumn{3}{|c|}{ Spirometry } \\
\hline $\mathrm{FEV}_{1}$ (litre) & $2.96 \pm 0.62$ & $2.68 \pm 0.62$ \\
\hline FVC (litre) & $3.07 \pm 0.68$ & $2.68 \pm 0.62$ \\
\hline \multicolumn{3}{|c|}{ Respiratory Muscle Strength } \\
\hline $\operatorname{MIP}\left(\mathrm{cmH}_{2} \mathrm{O}\right)$ & $77.71 \pm 25.78$ & $66.85 \pm 22.52$ \\
\hline MEP $\left(\mathrm{cmH}_{2} \mathrm{O}\right)$ & $76.35 \pm 21.61$ & $62.53 \pm 15.85$ \\
\hline
\end{tabular}

\section{Statistical Analysis}

The data of respiratory function were compared between the smoker and non-smoker groups using the independent t-test for normally distributed data or the Mann-Whitney U test for other distributions. Differences were considered statistically significant at $\mathrm{p}<0.05$.

\section{Results}

Most subjects started cigarette smoking between the ages of 15 to 18 years. The most common duration of cigarette smoking was 1-3 years and the maximal number of cigarettes smoked per day was less than or equal to 10 cigarette per day. Three major parameters, chest expansion, lung function using spirometry, and respiratory muscle strength, were compared. The chest expansion of the non-smoker group was significantly greater than that of the smoker group. There were significant differences in the chest circumference at the axilla level.

\section{Discussion}

Comparing this study's observations with some of the others which have found that whereas older symptomatic adult smokers with histories of large numbers of pack years may have lower FVC levels than non-smokers, young adult smokers have FVC levels equivalent to or higher than age equivalent non-smokers [7]. It is possible that at the time they started smoking and then with the subsequent growth maturation years, particularly in the very early twenties, they had developed somewhat larger lungs and thus experienced no discomfort on smoking which led to their smoking on regular basis [8]. In this study also, greater FVC values and the development of greater height in the smokers fortifies the above observation made by these studies. This study also reports that the young adults with subsequent growth maturation developed greater inspiratory and expiratory muscle strength, however with the growth in age this study showed no significant difference when compared with the respiratory pressures [9-11]. In this study, all parameters of chest expansion of the non-smoking youths were greater than those of the smoking youths. Decreased chest circumference at the axillary level was associated with reductions in the AP and ML diameters.

This is because chest expansion at the axillary level represents the upper chest breathing pattern, which utilizes a combination of upward and forward chest movements or the pump-handle movement, as well as upward and outward chest movements or the bucket handle movement. This result suggests that cigarette smoking affects the upper chest expansion of smoking youths. A reduction in chest expansion arising from reduced chest wall motion and flexibility would affect the performance and work of breathing, suggesting a vulnerability to dyspnea. Thus, the early stage of smoking among youths does cause reduction in the lung function. Inhaled cigarette smoke has been shown to elicit acute changes in respiratory function including alterations in resistance to airflow, coughing, and irritation of the airways. Our research findings may encourage the implementation of smoking cessation counseling for adolescents. The spirometer is commonly used for measuring respiratory function for diagnostic and clinical purposes. However, fluctuations in our data may have been caused by miscommunication with the subjects.

\section{Conclusion}

It is concluded that most of the people started smoking in young age due to environmental and social factors. It is also observed that chest expansion is greater in smokers as compared to non-smokers and smokers suffer ore from respiratory diseases as compared to non-smokers.

\section{References}

1. Burchfiel CM, Marcus E, Maclean C, Curb JD, Vollmer WM, et al. (1995) Effects of smoking and smoking cessation on longitudinal decline in pulmonary function. Am J Respir Crit Care Med 151(6): 1778-1785.

2. Zamel N, Altose MD, Speir WA (1983) Statement on spirometry: A report of the section of respiratory pathophysiology of the American College of Chest Physicians. J Asthma 20(4): 307-311.

3. Walter S, Nancy NR, Collier CR (1979) Changes in the force expiratory spirogram in young male smokers. Am Rev Respir Dis 119(5): 717-724.

4. Emery S, Gilpin EA, White MM, Pierce JP (1999) How adolescents get their cigarettes Implications for policies on access and price. J Nat Cancer Inst 91(2): 184-186.

5. Giovino GA, Schooley MW, Zhu BP, Chrismon JH, Tomar SL, et al (1994) Surveillance for selected tobacco-use behaviors-United States, 1900-1994. MMWR CDC Surveill Summ 43(3): 1-43. 
6. Hapman S, Borland R, Scollo M, Brownson RC, Dominello A, et al (1999) The impact of smoke-free workplaces on declining cigarette consumption in Australia and the United States. Am J Public Health 89(7): 1018-1023.

7. Ambrose JA, Barua RS (2004) The pathophysiology of cigarette smoking and cardiovascular disease: An update. J Am Coll Cardiol 43(10): 17311737.

8. Fagerstrom KO (1989) Measuring nicotine dependence: A review of the Fagerstrom Tolerance Questionnaire. J Behav Med 12(2): 159-182.

\section{ISSN: 2574-1241}

DOI: $10.26717 / B J S T R .2018 .07 .001570$

Murad Mehmood. Biomed J Sci \& Tech Res

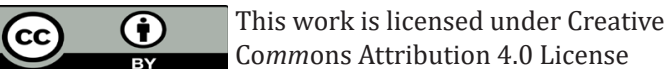

Submission Link: https://biomedres.us/submit-manuscript.php
9. Xu X, Dockery D, Ware J, Speizer FE, Ferris BG (1992) Effects of cigarette smoking on rate of loss of pulmonary function in adults: a longitudinal assessment. Am Rev Respir Dis 146(5 Pt 1): 1345-1348.

10. Pierce JP, White MM, Messer K (2009) Changing age-specific patterns of cigarette consumption in the United States, 1992-2002: association with smoke-free homes and state-level tobacco control activity. Nicotine Tob Res 11(2): 171-177.

11. Shiffman S (2009) Light and intermittent smokers: background and perspective. Nicotine Tob Res 11(2): 122-125.

$\begin{array}{ll}\text { BIOMEDICAL } & \text { Assets of Publishing with us } \\ \text { RESEARCHES } & \text { Global archiving of articles } \\ & \text { - Immediate, unrestricted online access } \\ & \text { - Rigorous Peer Review Process } \\ & \text { - Authors Retain Copyrights } \\ \end{array}$

